\title{
DESENVOLVIMENTO DE JOGOS DIDÁTICOS AUXILIARES EM PRÁTICAS TRANSDISCIPLINARES E DA ALFABETIZAÇÃO CIENTÍFICA NO ENSINO DAS CIÊNCIAS DA NATUREZA
}

\section{Development of auxiliary didactic games in transdisciplinary practices and scientific literacy in the teaching of natural sciences}

\author{
Isabela Vieira da Silva (isabelavdsilva@gmail.com) \\ Universidade Federal de Juiz de Fora (UFJF) \\ Layla Mayer Fonseca (laylamayer.fonseca@gmail.com) \\ Universidade Federal de Juiz de Fora (UFJF) \\ Cristiana da Silva Tavares (cristiana.tavares@gmail.com) \\ E. E. Cel. Antônio Alves Teixeira (EECAAT) \\ Cristina da Silva Tavares (cristinadasilvatavares@gmail.com) \\ E. E. Professor Teodoro Coelho (EEPTC) \\ Ana Maria do Carmo (anadcarmo@yahoo.com.br) \\ E. M. Engenheiro André Rebouças (EMEAR) \\ Antonio Carlos Sant'Ana (antonio.sant@ufjf.edu.br) \\ Universidade Federal de Juiz de Fora (UFJF)
}

\begin{abstract}
Resumo: Neste estudo estão relatadas as atividades desenvolvidas em escolas públicas de Juiz de Fora, MG, pelo grupo de trabalho formado por licenciandos bolsistas do subprojeto de Ciências, Ciclo II, do Programa Institucional de Bolsas de Iniciação à Docência (PIBID), da Universidade Federal de Juiz de Fora (UFJF). Os projetos pedagógicos desenvolvidos tiveram por base as propostas da Carta da Transdisciplinaridade que envolvem diálogos entre os conteúdos disciplinares e as realidades social, econômica e cultural dos alunos. Outro objetivo presente nos projetos foi a construção de ações que permitissem o desenvolvimento da alfabetização científica dos alunos, compreendida como a capacidade de dar significado aos conceitos científicos. A produção de jogos didáticos, privilegiando sempre cartas com textos e regras pelas quais a leitura das cartas devesse ser realizada pelos próprios jogadores, foi a principal ferramenta para eficientemente conciliar a proposta transdisciplinar com a busca da alfabetização científica.
\end{abstract}

Palavras-chave: Jogos didáticos; Lúdico; Ensino de Ciências; Ensino Fundamental. 
Abstract: This study reports activities carried out in public schools in Juiz de Fora, Minas Gerais, Brazil, by the work group formed by scholarship holders from the subproject named Sciences, Cycle II, from the Program of Institutional Scholarship for Initiation to Teaching (Programa Institucional de Bolsas de Iniciação à Docência PIBID) from Universidade Federal de Juiz de Fora (UFJF). The pedagogical projects developed were based on the proposals of the Charter of Transdisciplinarity that involve dialogues between the disciplinary contents and the social, economic and cultural realities of the students. Another objective of the project was the construction of actions that allowed the development of the scientific literacy in the students that is understood as an ability to give meaning to scientific concepts. The production of didactic games, always favoring cards with texts and rules by which the reading of the cards should be performed by the players themselves, was the main tool to efficiently reconcile the transdisciplinary proposal with the seeking for scientific literacy.

Keywords: Educational games; Ludic; Science Teaching; Elementary Scholl.

\section{INTRODUÇÃO: O SUBPROJETO INTERDISCIPLINAR DE CIÊNCIAS CICLO II}

O Programa Institucional de Bolsas de Iniciação à Docência (PIBID) financiado pela Coordenação de Aperfeiçoamento de Pessoal de Nível Superior (Capes) é uma iniciativa para o aprimoramento dos cursos de formação de professores e valorização dos professores da Educação Básica como colaboradores na formação dos futuros professores.

O subprojeto Interdisciplinar de Ciências Ciclo II do PIBID da Universidade Federal de Juiz de Fora (UFJF) teve início em setembro 2012 e até fevereiro de 2018, envolveu cinco escolas parceiras: E. E. Cel. Antônio Alves Teixeira, E. E. Professor Teodoro Coelho, E. M. Engenheiro André Rebouças, E. M. Antônio Carlos Fagundes e E. M. Professora Thereza Falci.

Nestes cinco anos foram desenvolvidas diversas atividades nas escolas parceiras buscando, em uma perspectiva transdisciplinar, aprimorar as habilidades de leitura e interpretação de texto dos alunos, entendendo que esta é uma tarefa que também compete à disciplina de Ciências da Natureza, em um contexto em que os conteúdos programáticos dialogassem com a realidade dos alunos. Uma vez que "sendo a leitura um processo interativo e fundamental para formar leitores ativos e críticos, torna-se 
fundamental incluir os professores de todas as áreas de ensino em práticas constantes de leitura" (PEREIRA; LIMA, 2018, p. 35). Além disto, Pereira e Lima (2018) destacam ainda, a importância destas leituras serem realizadas de maneira interdisciplinar "visando a interação entre os assuntos e o desenvolvimento da competência leitora dos estudantes" (p. 35).

\section{TRANSDISCIPLINARIDADE E O ENSINO DE CIÊNCIAS}

Muito se tem refletido sobre o Ensino das Ciências da Natureza para que este permita ao aluno dialogar com as diferentes realidades presentes em sua vida. Esse diálogo, por sua vez, deverá incorporar a problemática das relações entre os alunos e a comunidade em que vivem. No entanto, o espaço próximo a eles está cada vez mais aberto a um mundo globalizado, em que a informação flui hipertrofiada pelas mídias digitais. As interfaces presentes nas mais diversas proposições e ações, pensadas no âmbito da escola e envolvendo diferentes temas de estudo, são múltiplas neste ambiente tão complexo.

No arcabouço desta discussão, surge o conceito de transdisciplinaridade, como uma proposta de pensar o ensino como um processo de problematização dos conteúdos, de maneira integrada e em um contexto global. Almeja-se a criação de proposições reflexivas ao redor dos objetos em estudo, que se relacionem às temáticas ligadas ao aluno, com o envolvimento de diferentes áreas do conhecimento, permitindo integrar questões econômicas, sociais, culturais e do meio ambiente. Isto passa pelo estabelecimento de um diálogo entre o aluno, os materiais de referência (textos e mídias) e os problemas que vivencia.

Desta maneira, as ações que o aluno realiza na sua comunidade devem conectar-se com o conhecimento apresentado em sala de aula, dialogando com demandas locais, regionais e globais. A construção dos conceitos deve permitir a observação da interdependência entre os vários temas de estudo e, de algum modo, levar o aluno a sentir-se pertencente ao tema estudado. As ações propostas no processo educativo devem ser sempre desafiadoras e inovadoras, pois não podem ser passivas em um ambiente permanente de mudanças.

A complexidade inerente aos conteúdos programáticos, quando se estabelece o diálogo destes com a realidade do aluno, permite uma analogia com a diversidade das 
relações ecológicas, em que vários sistemas interdependentes não podem se isolar do todo, incluindo o sistema em estudo (MORIN, 2003).

Esta proposta de reflexão sobre o processo educativo, defendida por vários autores da atualidade, levou à construção da Carta da Transdisciplinaridade em 1994 (SOMMERMAN; MELLO; BARROS, 2002). A visão de uma educação interdisciplinar e transdisciplinar foi incorporada às proposições da Organização das Nações Unidas para a Educação, a Ciência e a Cultura (UNESCO), como tema relevante para repensarmos os objetivos da educação e do ensino das Ciências da Natureza em particular. Entre os quinze artigos que compõem a carta, podem ser destacados:

\begin{abstract}
Artigo 3: A transdisciplinaridade é complementar à aproximação disciplinar: faz emergir da confrontação das disciplinas dados novos que as articulam entre si [...] A transdisciplinaridade não procura o domínio sobre as várias outras disciplinas, mas a abertura de todas elas àquilo que as atravessa e as ultrapassa (SOMMERMAN; MELLO; BARROS, 2002, p. 194).
\end{abstract}

Artigo 13: A ética transdisciplinar recusa toda atitude que se negue ao diálogo e à discussão [...] O saber compartilhado deveria conduzir a uma compreensão compartilhada, baseada no respeito absoluto das diferenças entre os seres, unidos pela vida comum sobre uma única e mesma Terra (SOMMERMAN; MELLO; BARROS, 2002, p. 196).

A definição de transdisciplinaridade, como concebida por Nicolescu et al. (1999), representa a integração do conhecimento pelo diálogo entre as disciplinas e destas com o mundo:

\begin{abstract}
A transdisciplinaridade, como o prefixo 'trans' indica, diz respeito àquilo que está ao mesmo tempo entre as disciplinas, através das diferentes disciplinas e além de qualquer disciplina. Seu objetivo é a compreensão do mundo presente, para o qual um dos imperativos é a unidade do conhecimento (NICOLESCU et al., 1999, p. 11).
\end{abstract}

\title{
3. ALFABETIZAÇÃO E LETRAMENTO CIENTÍFICOS
}

A preocupação com a capacidade do indivíduo em dominar as habilidades de leitura e escrita, necessárias para uma participação efetiva e competente nas práticas sociais e profissionais é motivo de grande preocupação no Brasil. No exame do Programa de Avaliação Internacional de Estudantes (Programme for International Student Assessment - PISA), realizado em 2015, o Brasil ficou na $61^{\text {a }}$ posição em domínio de leitura e na $65^{\mathrm{a}}$ posição em conhecimentos sobre Ciências entre 72 países 
avaliados. Este problema persiste há muito tempo no sistema educacional brasileiro. Soares (2004) destaca que muitos cidadãos classificados nos censos nacionais como detentores da leitura e escrita podem ser classificados como analfabetos funcionais.

Há, então, uma necessidade premente envolvida nas ações de educar, ensinar, compreender, refletir e agir com criticidade, que implica na capacidade do sujeito interagir com informações diversas em um mundo midiático, principalmente através de textos. A efetividade destas ações é indiscutivelmente dependente da capacidade de leitura e do nível de letramento e, em particular, do letramento científico (LC) que a pessoa possui.

Deste modo, inicialmente, faz-se necessário, um olhar para a discussão a respeito dos conceitos de alfabetização e letramento. A alfabetização pode ser considerada como o ensino das habilidades de ler e escrever ao criar as relações entre os fonemas e o sistema gráfico (SOARES, 2004). A partir da década de 1990 esse conceito passou a ser vinculado a outro definido como letramento e associado às capacidades de entender $\mathrm{e}$ integrar as informações lidas.

Assim, a alfabetização pode ser caracterizada como o ensino da língua materna ao indivíduo, onde ele aprende a grafia de seu idioma, juntamente com todas as peculiaridades na identificação das relações fonema-grafema. Já o letramento consiste em despertar o que foi aprendido na alfabetização, pelo desenvolvimento da funcionalidade na leitura e na escrita, que é uma habilidade básica ao caminhar-se para a capacidade de análise frente à informação.

Seguindo esta mesma linha de pensamento, Santos (2007) concorda que o letramento está em grau acima da alfabetização e conceitua a alfabetização científica (AC) como o domínio da linguagem científica, enquanto o LC estaria relacionado ao uso do conhecimento científico na prática social.

Krasilchik e Marandino (2004) reforçam objetivamente a distinção entre AC e LC, inserindo este no âmbito do estabelecimento das correlações entre os conceitos científicos e a realidade:

Se ampliarmos essa definição de letramento para o âmbito da ciência, entendemos que ser letrado cientificamente significa não só saber ler e escrever sobre ciência, mas também cultivar e exercer as práticas sociais 
envolvidas com a ciência; em outras palavras fazer parte da cultura científica (KRASILCHIK; MARANDINO, 2004, p. 22).

Laugksch (2000 apud SANTOS, 2007) "define LC com função social como a capacidade mínima funcional para agir como consumidor e cidadão" (p. 480). O que seria a capacidade mínima para compreender criticamente reportagens, notícias, fatos, ou seja, os processos e problemas que estão envolvidos na dinâmica da sociedade e que estejam associados às ciências.

O caminho entre o desenvolvimento da criticidade pelo letramento e a formação de um sujeito socialmente responsável e pleno de direitos não é simples (PAULA; LIMA, 2007), mas permitindo-se pensar em níveis de letramento, o caminho começa no Ensino Fundamental (PEREIRA; LIMA, 2018; SASSERON; CARVALHO, 2008). Desse modo, a busca pelo letramento neste nível de ensino passa por apresentar às crianças diferentes experiências com a leitura e a escrita, sempre vinculadas ao estabelecimento das correlações entre os conceitos abordados e a interpretação do mundo que a cerca (PEREIRA; LIMA, 2018).

Diante disso, a busca por um LC que leve ao desenvolvimento das capacidades de refletir e agir frente as práxis cotidianas, é um modelo de ensino que dialoga com a abordagem "Ciência Tecnologia e Sociedade" (CTS), que por sua vez também pode ser pensada em um contexto transdisciplinar.

Para que se atinja, portanto, o LC deve-se buscar um currículo que inove o Ensino de Ciências nas escolas, destacando três pontos: a natureza das ciências, a linguagem científica e seus aspectos sociais e científicos. Para isso, Vieira e Oliveira (2010, p. 2), apontam um caminho, onde dizem que:

[...] os jogos e as brincadeiras são instrumentos pedagógicos importantes e determinantes para o desenvolvimento da criança, pois no jogar e no brincar as mesmas desenvolvem habilidades necessárias para o seu processo de alfabetização e letramento.

Visto que através deles os alunos "adquirem diversas experiências, interagem com outras pessoas, organizam seu pensamento, tomam decisões, desenvolvem o pensamento abstrato e criam maneiras diversificadas de jogar, brincar e produzir conhecimentos" (VIEIRA; OLIVEIRA, 2010, p. 2). 
4. DESENVOLVIMENTO

DE

JOGOS

DIDÁTICOS

TRANSDISCIPLINARES AUXILIARES ÀS PRÁTICAS DE LEITURA ENTRE OS ALUNOS

O uso de jogos é amplamente citado na literatura especializada em Educação como particularmente eficiente para incentivar, socializar e gerar confiança nos alunos com maiores dificuldades de aprendizado, bem como, mediar processos de ensino e de aprendizagem.

Como observado por Soares (2016, p. 9) "a palavra Jogo tem uma quantidade grande de significados, principalmente na língua portuguesa". Na busca de uma definição, no contexto deste trabalho, considerou-se jogo didático que, segundo Cunha (2012, p. 95), “está diretamente relacionado ao ensino de conceitos e/ou conteúdos, organizado com regras e atividades programadas e que mantém um equilíbrio entre a função lúdica e a função educativa do jogo, sendo, em geral, realizado na sala de aula ou no laboratório". Godoi (2010, p. 22) enfatiza que vinculado aos conteúdos disciplinares os

[...] jogos podem ser considerados educativos se desenvolverem habilidades cognitivas importantes para o processo de aprendizagem, tais como resolução de problemas, percepção, criatividade, raciocínio rápido, dentre outras. Quando um jogo é elaborado com o objetivo de atingir conteúdos específicos para ser utilizado no meio escolar, este é denominado de jogo didático.

Além disso, os jogos podem servir como estratégias para produção de vínculos entre os conteúdos programáticos e as questões socioculturais demandadas por um ensino transdisciplinar (MEIRELLES; SANT'ANA; LOPES, 2015), favorecem também a formação cidadã dos alunos, pois podem contribuir

\footnotetext{
para o entendimento de regras e valores que decorrem dos jogos, bem como o respeito ao próximo e desenvolvimento de habilidades relacionadas ao raciocínio lógico, motricidade, senso de responsabilidade, estímulo à cooperação, dentre outros. Além disso, pode contribuir para superar as limitações do ensino conteudista, permitindo o desenvolvimento da habilidade de resolver problemas, favorecer a compreensão de conceitos e enriquecer as experiências pessoais entre professor e aluno (ALIANE et al., 2018, p. 106-107).
}

Nesse sentido, Leão (2015, p. 650) complementa que os jogos permitem desenvolver habilidades e competências que não seriam alcançadas pelas estratégias mais tradicionais de ensino, com ênfase em alfabetização e letramento: 
[...] o uso de jogos pode despertar nas crianças a motivação, a expressividade, a imaginação, a linguagem comunicativa, a atenção, a concentração, o raciocínio lógico, e podem englobar diferentes áreas do conhecimento, por isso constitui-se em um recurso de ponta no processo de alfabetização/letramento.

Seguindo este contexto e a fim de desenvolver a alfabetização científica dos alunos, os licenciandos - bolsistas do PIBID Ciências - Ciclo II - junto com as supervisoras deste mesmo subprojeto, desenvolveram instrumentos didáticos diversos, priorizando a produção de jogos transdisciplinares que abordassem conteúdos específicos e contextualizados na perspectiva da comunidade escolar. Para este trabalho a seguir apresentamos três exemplos que foram utilizados com diferentes turmas e distintas escolas.

O jogo denominado "A ciência na sua vida", inspirado por um jogo já existente denominado de Perfil, foi confeccionado artesanalmente pelos bolsistas do PIBID (Figura 1), com ampla participação dos alunos das escolas participantes: escolha do nome e do desenho que ilustrou o tabuleiro do jogo. Foram confeccionadas quarenta cartas e em cada uma havia uma palavra-chave e doze frases associadas a ela. Os temas escolhidos são relacionados às Ciências, como: água, solo, lixo, efeito estufa, desmatamento, doenças, entre outros.

No tabuleiro havia casas desenhadas e quatro pinos para quatro jogadores avançarem até o final. Um quinto aluno lia as dicas para que os jogadores descobrissem a palavra-chave. Quem respondesse corretamente, jogava o dado e avançava. Aquele que avançasse no jogo com o menor número de dicas ganhava bônus. Este jogo oportunizou aos participantes a consolidação de conceitos importantes sobre os temas abordados em aula, além do aprimoramento da oralidade e da leitura. 


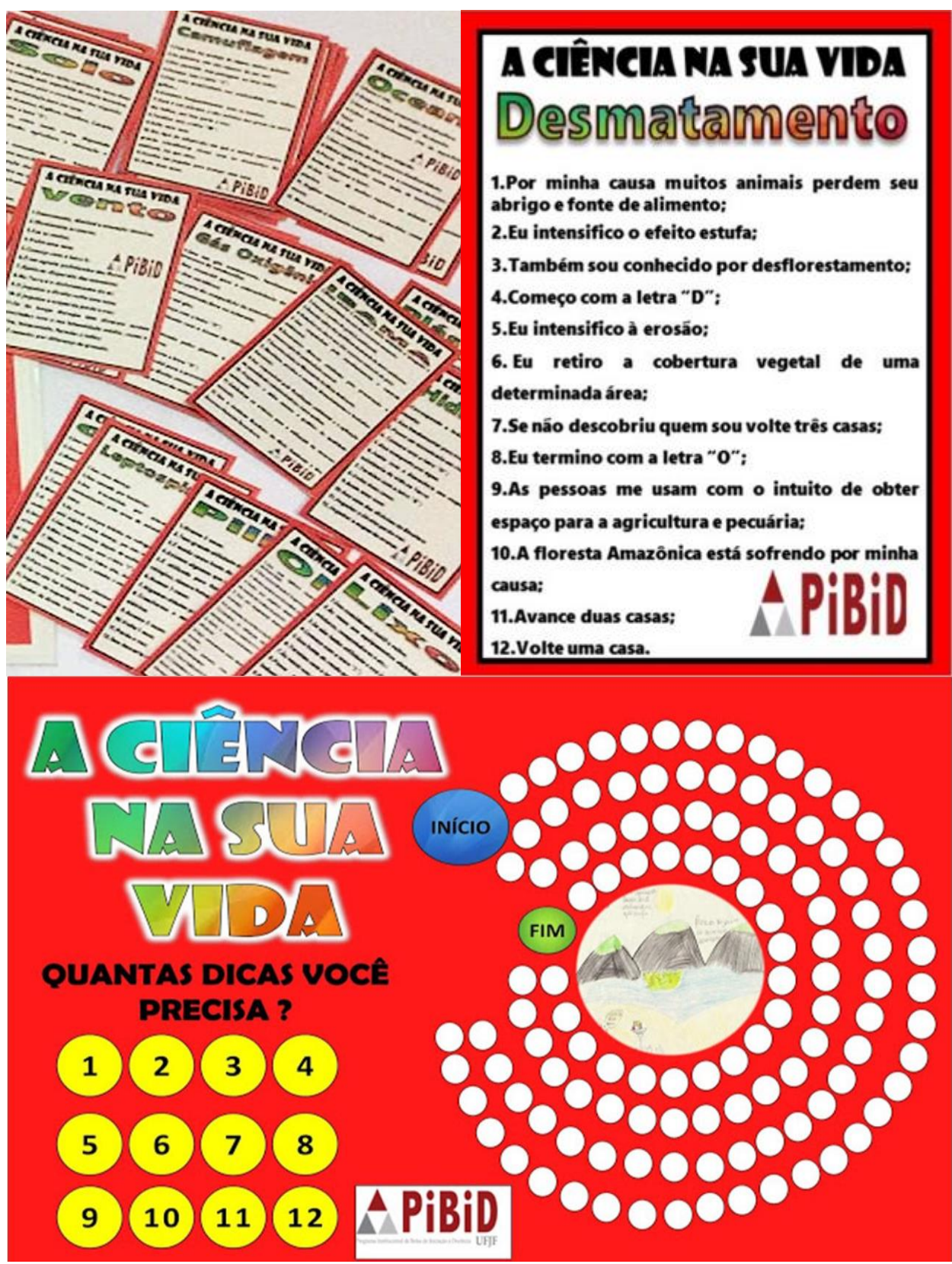

Figura 1 - Tabuleiro e cartas do jogo "A ciência na sua vida" confeccionado pelos bolsistas e supervisoras do PIBID.

O jogo "Brincando com o tema água" foi produzido no formato parecido com o jogo citado anteriormente: tabuleiro com pinos para quatro jogadores e cartas com textos. No entanto, este envolveu apenas um tema gerador, neste caso, a água.

Com relação às cartas do jogo existiam dois tipos: aquelas com questões de múltipla escolha e outras com curiosidades - você sabia? (Figura 2). Em cada carta havia uma pergunta e algumas alternativas com apenas uma correta, o aluno mediador 
lia a carta e o jogador que acertasse a resposta avançava as casas com o intuito de chegar ao final.
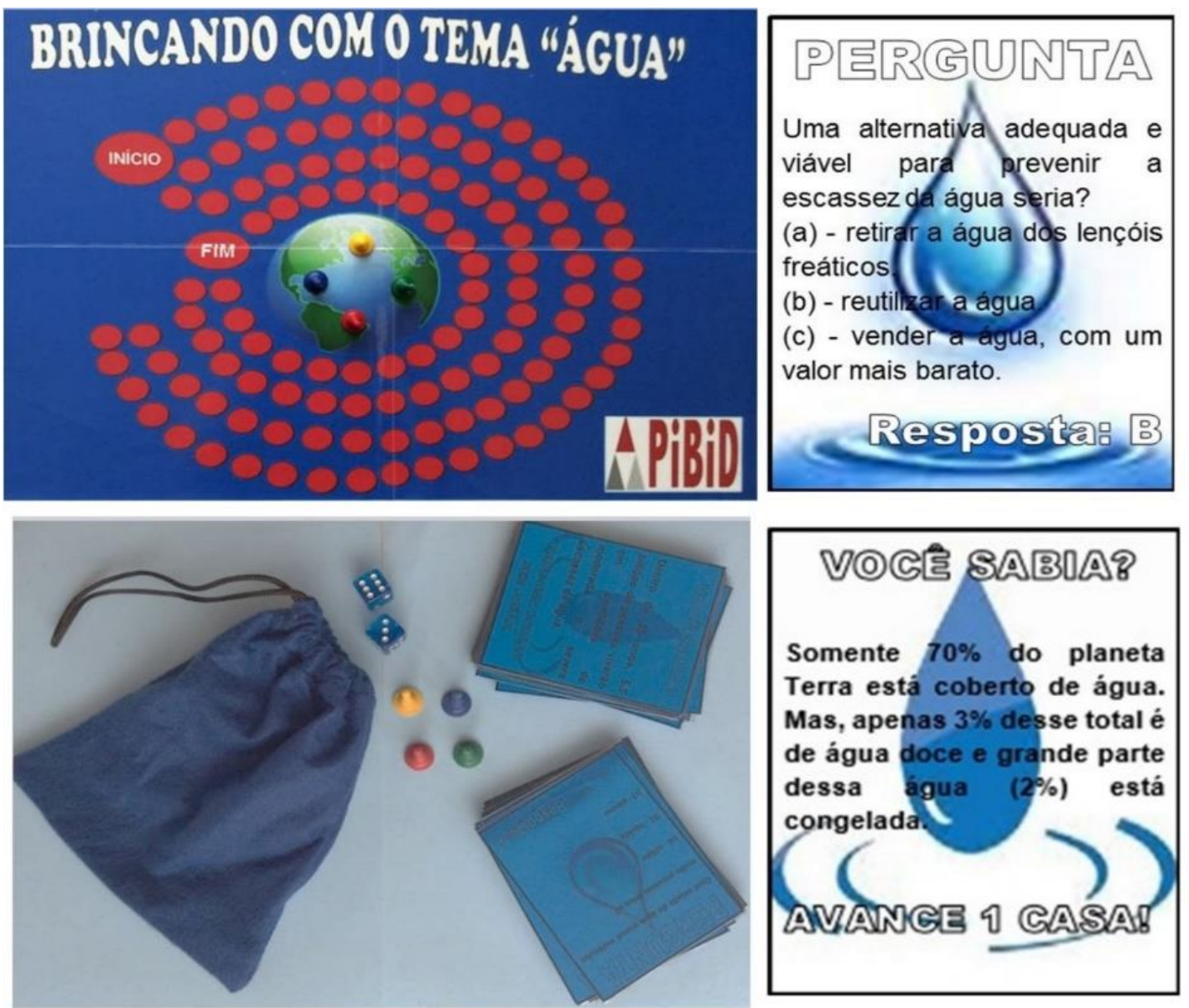

Figura 2 - Tabuleiro e cartas do jogo "Brincando com o tema água" confeccionados pelos bolsistas e supervisoras do PIBID Ciências Ciclo II da UFJF.

Por fim, o terceiro jogo - "Microinvestigação" (Figura 3) - teve como inspiração o jogo de tabuleiro Detetive e foi confeccionado para o desenvolvimento dos temas doenças, fenômenos biológicos, seres vivos, estruturas biológicas e processos químicos relacionados aos microrganismos. 


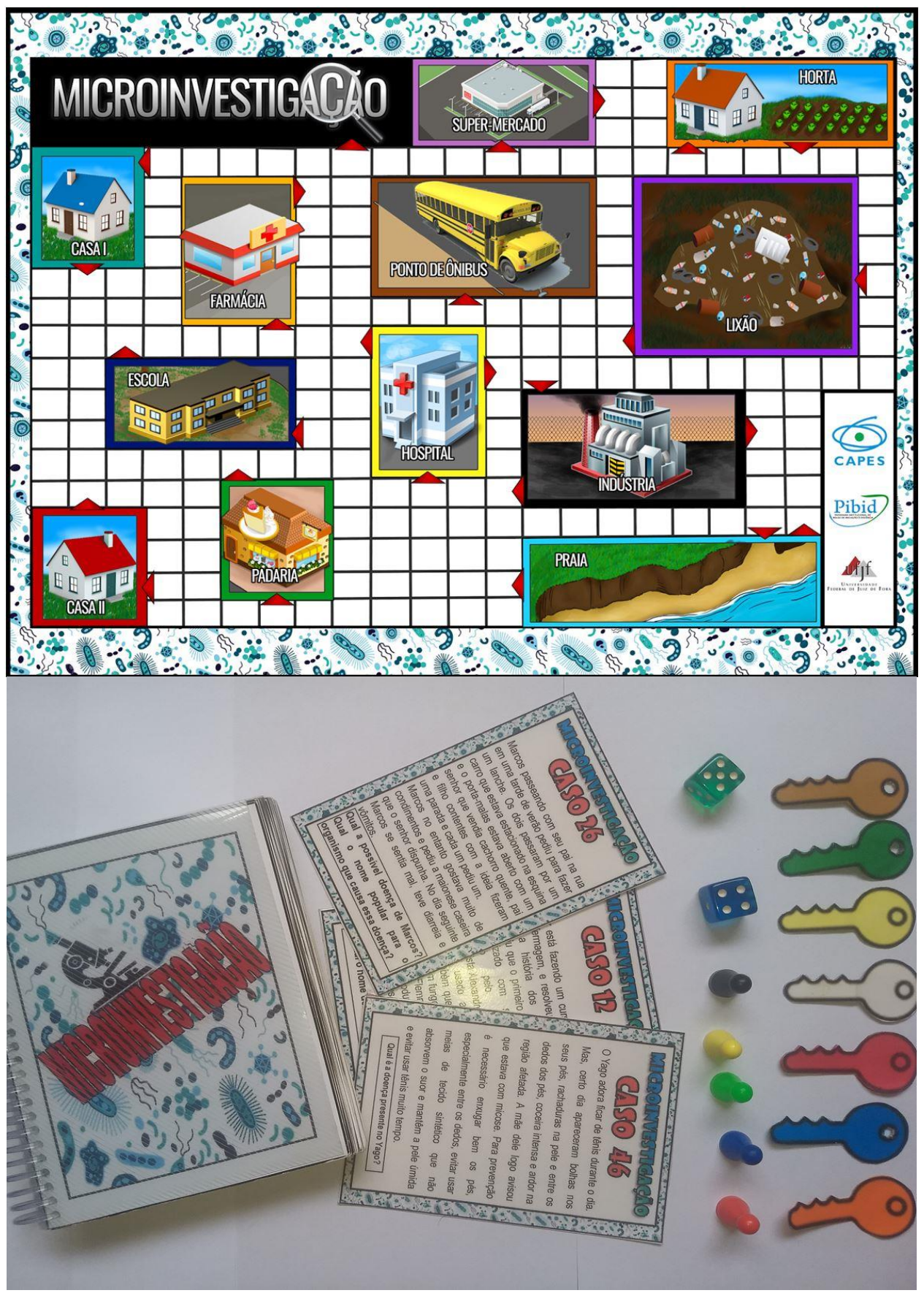

Figura 3 - Tabuleiro, livro e cartas do jogo "Microinvestigação" confeccionados pelos bolsistas e supervisoras do PIBID Ciências Ciclo II da UFJF.

As cartas com relatos de casos e o livro traziam informações e uma pergunta sobre o enigma em questão. O tabuleiro possuía locais do cotidiano, como: casa, escola, padaria, ponto de ônibus, entre outros, que permitiam ao aluno buscar dicas no livro para solucionar o caso. O ponto de partida para as rodadas do jogo eram as casas I e II. As chaves eram utilizadas para "trancar" ou "paralisar" o adversário em um dos 
ambientes por uma rodada. Os pinos representavam cada jogador e os dados definiam o andamento do jogo.

Apesar da leitura de textos ser uma necessidade durante os jogos, estes apresentaram boa receptividade dos alunos, mesmo por aqueles que possuíam maior dificuldade nesta competência, sendo desafiadores para a maioria dos alunos, mas, principalmente, para aqueles que possuíam menor nível de leitura, e que insistiram em participar. Esses, em outros contextos, eram rotineiramente excluídos ou se negavam a participar das atividades de leitura em sala.

A aplicação desses jogos visou, além do processo de $\mathrm{AC}$ envolvendo todos os alunos, o aprimoramento do LC daqueles que, motivados pela atividade lúdica, avançaram mais nas reflexões propostas. A efetividade destas ações pôde ser verificada pela avaliação que os alunos fizeram destas atividades, como nos textos da Figura 4.
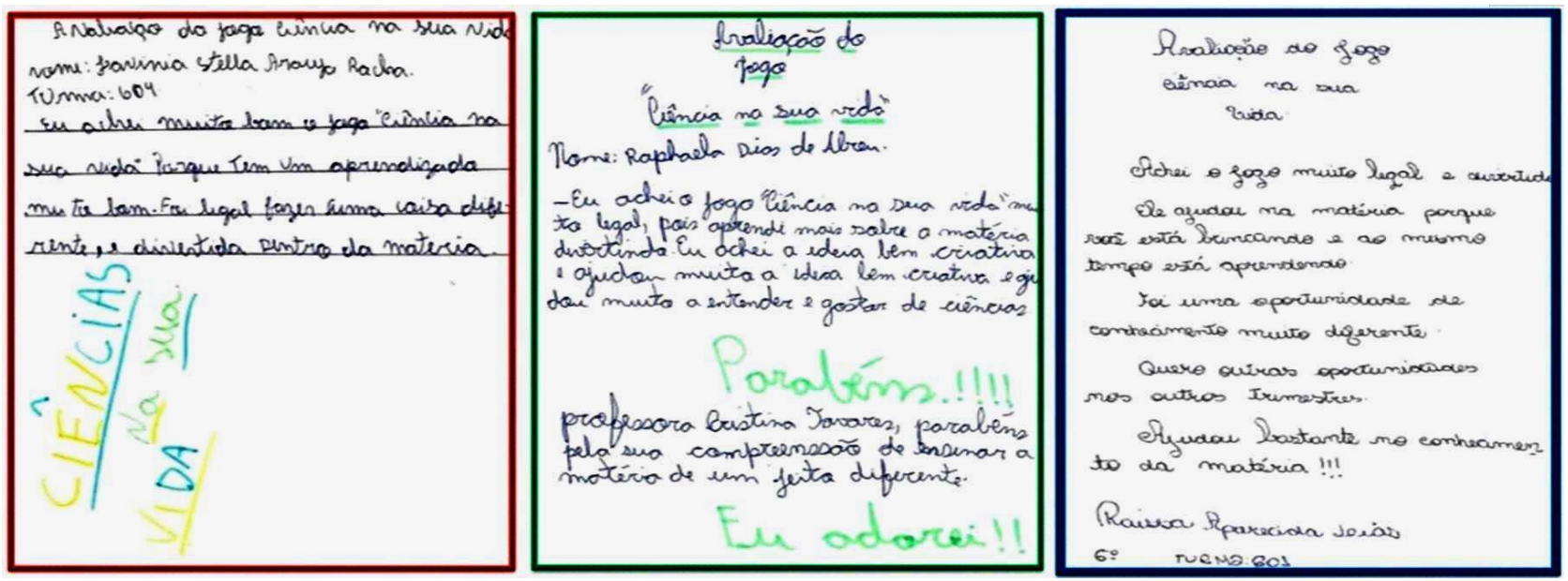

Figura 4 - Textos produzidos pelos alunos avaliando as atividades realizadas com os jogos.

O interesse desperto levou à busca dos alunos pelo uso dos jogos para além do momento das aulas, mostrando que o lúdico despertou o interesse, a criatividade e o gosto do aluno pela Ciência. Leodoro (2008) afirma que "a criança, envolvida na atividade lúdica, participa ativamente na construção do seu conhecimento sobre ciência e tecnologia e na apreensão do entorno tecnocientífico" (p. 107). Zismann, Bach e Wenzel (2019) complementam ainda que "a prática da leitura é essencial nos processos de ensino, pois proporciona o desenvolvimento da imaginação, da criatividade, da comunicação e do posicionamento crítico frente ao texto" (p. 128). Assim, o uso dos jogos permitiu inserir a leitura e a interpretação de textos como atividades de maior 
alcance entre os alunos.

O lúdico tornou-se educativo ao despertar a curiosidade sobre o mundo e a vida, tornando-se um estímulo às descobertas e criações e um instrumento auxiliar de práticas de leitura entre os alunos.

\section{CONSIDERAÇÕES FINAIS}

Os jogos didáticos proporcionaram o aprender de forma prazerosa, numa condição diferente da vivenciada pela aula expositiva, promovendo motivação, concentração, curiosidade e a integração dos alunos. Também permitiram ao professor a observação da oralidade e fluência da leitura de cada aluno durante toda a atividade, e sua interferência como mediador quando necessário.

Os jogos didáticos mostraram-se muito eficientes como estratégias para o aprimoramento da leitura entre os alunos e da alfabetização científica no Ensino Fundamental. Durante as práticas envolvendo os jogos observou-se situações na qual o aluno sentia-se motivado a participar e a ser o protagonista, não desistindo de jogar, mesmo com dificuldades para ler as cartas aos seus colegas.

Notou-se também, que aqueles alunos desmotivados, não participativos ou indisciplinados demonstraram outra postura perante os desafios dos jogos. Neste momento, estes alunos evidenciavam grande interesse em participar, sempre concentrado, inclusive na leitura, sendo muitas vezes o vencedor do jogo. Estes momentos lúdicos oportunizaram ganho notável nas interações de cada aluno com seus colegas e o professor, favorecendo a melhora nas relações interpessoais na sala de aula.

Ao professor, foi possível realizar avaliações mais específicas e pontuais de cada aluno, principalmente em relação à leitura e à oralidade. Ficou claro que o compromisso pela alfabetização é compromisso de todas as disciplinas e o caminho adequado tem reflexos diretos sobre o desempenho escolar.

\section{REFERÊNCIAS}

ALIANE, Cláudia S. de M.; REIS, Rita de Cássia; CÉSAR, Eloi T.; LOPES, José 
Guilherme da S. Lona periódica: promovendo reflexões em um processo de formação continuada com professores de química. REDEQUIM - Revista Debates em Ensino de Química , v. 4, n. 1, p. 102-129, 2018.

CUNHA, M. B. Jogos no ensino de química: considerações teóricas para sua utilização em sala de aula. Química Nova na Escola, v. 34, n. 2, p. 92-98, 2012.

GODOI, T. A. F.; OLIVEIRA, H. P.M; CODOGNOTO, L. Tabela periódica - um super trunfo para alunos do ensino fundamental e médio. Revista Química Nova na Escola, v. 32, n. $1,2010$.

KRASILCHIK, M.; MARANDINO, M. Ensino de Ciências e Cidadania. 1 ed. São Paulo: Moderna, 2004 (Coleção Cotidiano escolar).

LEODORO, M. P. Brincando com ciência e tecnologia: a utilização de brinquedos na educação científica das crianças. Ciência e criança: a divulgação científica para o público infanto juvenil. Rio de Janeiro: Fiocruz, 2008.

LEÃO, M. A. O uso de jogos como mediadores da alfabetização/letramento em sala de apoio das séries iniciais. Estudos Linguísticos, v. 44, n. 2, p. 647-656, 2015.

MEIRELLES, M. A.; SANT'ANA, A. C.; LOPES, J. G. S. Uma abordagem interdisciplinar envolvendo bioquímica e termoquímica através de um jogo pedagógico. In: Reflexões sobre formação de professores e ensino de química. São Paulo: Livr. da Física, p. 165-175, 2015.

MORIN, E. A cabeça bem-feita. Repensar a reforma, reformar o pensamento. Rio de Janeiro: Ed. Bertrand Brasil, 2003.

NICOLESCU, B.; PINEAU, G.; MATURANA, H.; RANDOM, M.; TAYLOR, P. Educação e Transdisciplinaridade. São Paulo: CETRANS, USP, 1999.

PAULA, H. F.; LIMA, M. E. C. C. Educação em Ciências, Letramento e Cidadania. Química Nova na Escola, v. 25, p. 3-9, 2007.

PEREIRA, Francine B.; LIMA, Siumara A. Leitura e ensino de ciências: estratégias de leitura para o gênero textual mapa. Experiências em Ensino de Ciências, v. 13, n. 3, p. 33-47, 2018.

SANTOS, W. L. P. Educação científica na perspectiva de letramento como prática social: funções, princípios e desafios. Revista Brasileira de Educação, v. 12, n. 36, p. 474-550, 2007.

SASSERON, L. H.; CARVALHO, A. M. P. Almejando a alfabetização científica no ensino fundamental: a proposição e a procura de indicadores do processo. Investigações em Ensino de Ciências, v. 13, n. 3, p. 333-352, 2008. 
SOARES , M. H. F. B. Jogos e atividades lúdicas no ensino de química: uma discussão teórica necessária para novos avanços. REDEQUIM - Revista Debates em Ensino de Química, v. 2, n. 2, Out. 2016.

SOARES, M. Letramento e alfabetização: as muitas facetas. Revista Brasileira de Educação, n. 25, p. 5-17, 2004.

SOMMERMAN, Américo; MELLO, Maria F. de; BARROS, Vitória M. de. (Orgs.) Educação e Transdisciplinaridade II. São Paulo: TRIOM, USP, UNESCO, 2002.

VIEIRA, L. S.; OLIVEIRA, V. X. A importância dos jogos e brincadeiras para o processo de alfabetização e letramento. Anais do V EPCT - Encontro de Produção Científica e Tecnológica. Faculdade Estadual de Ciências e Letras de Campo Mourão/Núcleo de Pesquisa Multidisciplinar. Alessandra Augusta Pereira da Silva (Org.). Campo Mourão: FECILCAM/NUPEM, 2010.

ZISMANN, Jonatan J.; BACH, Sabrina T.; WENZEL, Judite S. A leitura de texto de divulgação científica no ensino de cinética química. RIS - Revista Insignare Scientia, v. 2, n. 1, p. 127-137, Jan./Abr. 2019. 